\title{
Chinese Character Learning Information Platform Based on Multimedia Information Technology
}

\author{
Bochun Kang $\mathbb{D I}^{1}$ and Sicheng Kang ${ }^{2}$ \\ ${ }^{1}$ Anyang Preschool Education College, Department of Language and Literature, Anyang 455000, China \\ ${ }^{2}$ Northeast Agricultural University School of Electrical and Information, Harbin 150000, China \\ Correspondence should be addressed to Bochun Kang; kangbochun@ayyz.edu.cn
}

Received 3 January 2022; Revised 20 January 2022; Accepted 21 January 2022; Published 12 February 2022

Academic Editor: Xin Ning

Copyright (C) 2022 Bochun Kang and Sicheng Kang. This is an open access article distributed under the Creative Commons Attribution License, which permits unrestricted use, distribution, and reproduction in any medium, provided the original work is properly cited.

\begin{abstract}
MIT (multimedia information technology) has brought profound changes to education, and MIT teaching has become an effective teaching method. Based on the teaching concept of MIT and curriculum integration, the connotation and goal of MIT Chinese and the Chinese character learning information platforms are clarified. In this paper, the design of a Chinese character learning information platform based on MIT is chosen as the study object. Starting with the investigation and analysis of the application of multimedia teaching resources by teachers in oral Chinese teaching, the problems in the construction of Chinese teaching resources are summarized. This paper combines the characteristics of domain ontology with those in the process of word segmentation to disambiguate ambiguous fields by calculating the strength of semantic association, so as to maximize the speed of ambiguity identification and resolution without losing AR (accuracy rate). After experiments, the system found a balance between $\mathrm{RR}$ (recall rate), AR, and the speed of Chinese character segmentation.
\end{abstract}

\section{Introduction}

With the rapid development of the information age, MIT (multimedia information technology), represented by networking, digitalization, multimedia, and intelligence, is profoundly changing people's traditional ways of life, study, and work, profoundly affecting the contents and methods of modern education and teaching and promoting the information reform of education and teaching $[1,2]$. Traditional education is becoming increasingly difficult to meet the demands of modern society's rapid development, and it is an unavoidable choice for education to adapt to the future information society and cultivate high-quality talents [3]. The three-dimensional application of information means such as networks, animations, and numbers and intelligence in information-based Chinese teaching cannot only make complicated language knowledge interesting and visualized but also simplify key points and difficulties in Chinese teaching. Furthermore, the vivid and immersive communication environment created by a large amount of information can motivate students to participate actively in the classroom and maximize their Chinese learning potential [4].

For students to acquire knowledge, it is no longer just dependent on the granting of teachers' classroom knowledge, but maybe more from teachers and other media outside the classroom, which is not only for teachers' teaching ideas, teaching methods, and classroom teaching modes adopted by teachers [5]. Under the background of promoting educational informatization, the integration of MIT and various courses has become an inevitable requirement for promoting educational modernization and informatization, and the field of teaching Chinese characters should also meet this requirement. Multimedia-assisted teaching of spoken Chinese has changed the traditional teaching model of spoken Chinese, enriched the teaching content through sounds, pictures, words, and other forms, and provided students with a real language environment $[6,7]$.

In view of this, under the guidance of modern teaching theories such as constructivism and instructional design 
theory, this study attempts to design the Chinese character learning information platform based on MIT by referring to relevant research results at home and abroad and on the basis of investigating the usage and demand of the Chinese character learning information platform.

\section{Related Work}

At present, in foreign countries, Chinese education researchers in many countries are carrying out research based on multimedia-assisted Chinese teaching, and multimediaassisted Chinese teaching has become a research topic concerned by many foreign scholars. Literature [8] developed a hypertext-based, multiple-knowledge-sourcesbased intelligent Chinese teaching system. This system's teaching content includes pronunciation, stroke order, new words, grammar, sentence patterns, and grammar items, as well as the ability to diagnose errors. According to the literature $[9,10]$, it is necessary to reclarify classroom teaching content, reframe important and difficult points of knowledge, and at the same time, put forward many insights in teaching materials research. The research on classroom teaching skills based on teaching contents, classroom teaching skills based on class types, and nonverbal behavior learning and teaching skills of Chinese characters is presented in the literature [11]. Literature [12] investigates the theoretical issues surrounding the teaching of Chinese characters, such as language learning theory, language teaching theory, and cross-cultural communication theory. Literature $[12,13]$ investigates the connection between theory and practice from various perspectives.

Chinese is a monosyllabic language; each word corresponds to a syllable, and each syllable is composed of an initial consonant and a final consonant. The phenomenon of copronunciation in Chinese mainly refers to the pronunciation change between rhyme and vowel due to mutual influence [14]. With the deepening of research on Chinese character information processing, the problem of Chinese character text automatic segmentation has attracted considerable attention and become a frontier topic in Chinese character information processing. Forward maximum matching, reverse maximum matching, word-by-word traversal, setting segmentation marks, best matching, finite multilevel enumeration, word frequency statistics, adjacency constraint, expert system, minimum segmentation, neural network, and so on are some of the existing Chinese character segmentation algorithms $[15,16]$. Literature [17] found that introducing a statistical language model reduced the error rate of Chinese word segmentation by an order of magnitude. Literature [18] employs the rule-based method, which entails establishing some processing rules based on the characteristics of Chinese characters and then having the computer disambiguate the text using these processing rules. According to literature [19], this method can be used in a variety of industries. They later discovered, however, the efficiency of the rule-based word segmentation method was not as high as they had hoped. If special nouns that are not used or registered are not included, literature [20] uses a word segmentation method called "twice scanning association-backtracking," which has a segmentation accuracy rate of $98.6 \%$ and a running speed of 48 words/minute. A better maximum matching method, namely, maximum matching with positive increasing words, was proposed in the literature [21].

\section{Research Method}

3.1. Design of Chinese Character Learning Information Platform. The significance of designing the Chinese character learning information platform lies in that, on the one hand, teachers can easily find the required teaching resources from the library, such as excellent multimedia courseware and electronic lesson plans, and can also directly display pictures, sounds, animations, and video materials to students in classroom teaching through the network, thus enriching the classroom teaching content and improving the teaching quality of spoken Chinese; on the other hand, the teaching resource pool has a large amount of information, and the knowledge is updated quickly. Teachers can absorb new knowledge and update their own knowledge by using the resource pool so that their teaching personality can be publicized and their teaching level can be improved to a new level.

In the process of studying and designing the Chinese character learning information platform, standardization theory is the main basis. Specifically, it can improve the efficiency of material positioning, unify the interface design, coordinate among various functional modules, optimize the whole resource pool, and enhance the efficiency of using the resource pool. How to help teachers quickly and accurately search for the teaching resources they need is an important issue that cannot be ignored. Using the search function in the multimedia teaching resource library, you can easily locate the desired materials.

The purpose of the resource pool is to support the overall teaching goal as well as the teaching of the teachers. Based on the foregoing analysis and the author's research, the author believes that the multimedia resource library should have powerful multimedia storage, retrieval, and management functions and should be able to meet the needs of mass storage, quick retrieval, diverse media, easy operation, and convenient management. As a result, this paper follows the teaching syllabus of spoken Chinese teaching materials as the mainline and launches the concrete design of the Chinese character learning information platform, based on the actual needs of teachers and teaching materials.

The organizational structure of multimedia teaching resource database can be roughly divided into six parts: home page, course introduction, teaching resources, teaching materials, knowledge expansion, and online Q\&A. There are two contents in the first page, search and discipline trends. The specific system organization structure is shown in Figure 1.

Our goal is to design a hardware product that can facilitate learning Chinese, and is suitable for students and Chinese learners. It can display Chinese characters, take in the written information of users, take in the pronunciation information of users, process the information of users, and 


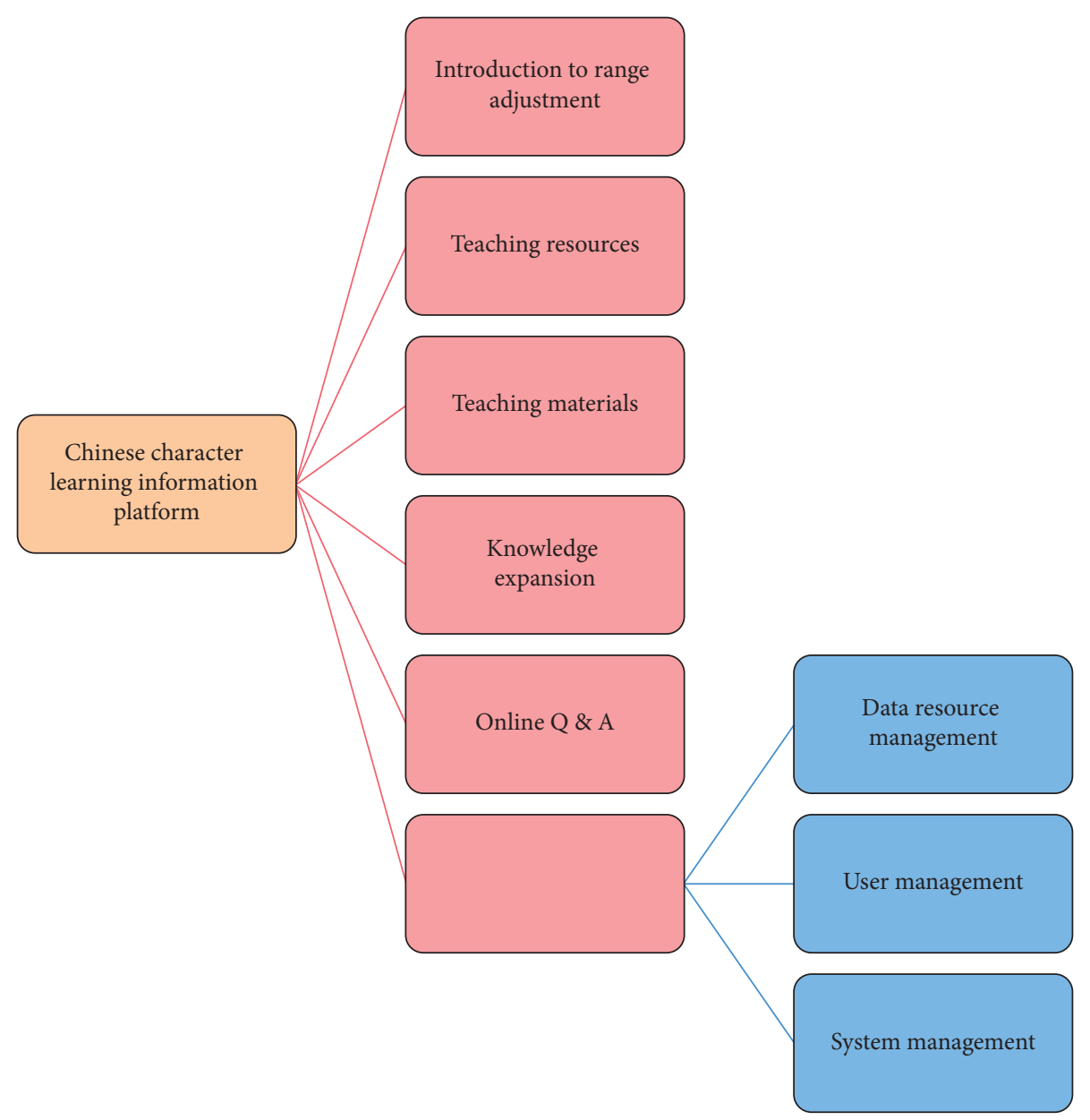

FIGURE 1: Organization chart of spoken Chinese multimedia teaching resource base.

feedback certain results to users. Besides feeding back the standard writing methods of Chinese characters to users, it is also necessary to be able to feedback the pronunciation of Chinese characters and even words and sentences to users so as to guide users' pronunciation. The handwriting analysis module is shown in Figure 2.

This module should complete the display of standard word stickers, the ingestion of the user's writing, the analysis of the user's writing, the feedback of results, and other functions.

The main issue in teaching a second language is deciding what to teach and how to teach it. What you teach and how you teach will have a direct impact on the acquisition effect of your students. The "Chinese character component recognition model" suffers from the same issue. What and how the model is trained will have a direct impact on the model's ability to learn Chinese characters. The main differences between the mother tongue and second language learner models are the training content and methods.

From the function of the platform, it can realize the organic combination of Chinese characters MIT and primary school literacy teaching. This combination is a comprehensive and pluralistic combination, which not only combines the curriculum, teaching, language, and writing
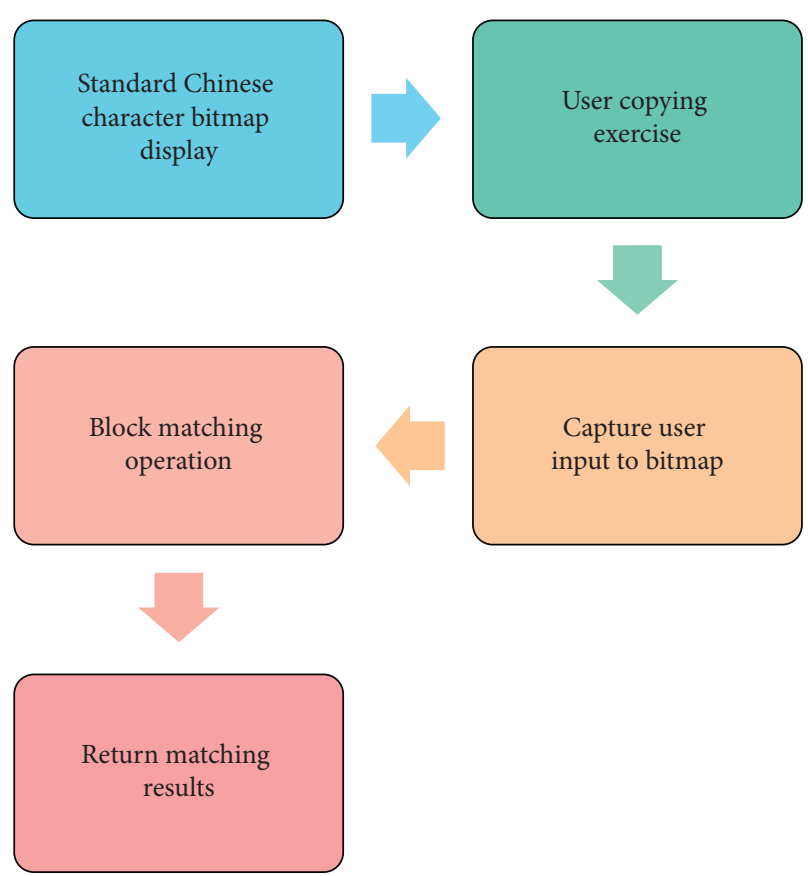

FIgURE 2: Handwriting analysis module. 
but also students' psychology and growth. Therefore, there is a need to accurately grasp the concepts of education and Chinese characters and accurately reflect and fully grasp the teaching objectives and requirements of literacy. Therefore, the establishment of the Chinese character learning information platform should first consider its scientific nature.

In view of the diverse individual differences in learning foundation, classroom learning time, and learning motivation of learners of Chinese characters, the author believes that the current research on the knowledge dissemination of Chinese characters should not be confined to the cage of traditional classroom teaching. While thinking about "how to teach," grasp the characteristics of students and pay more attention to the cognitive abilities of learners. Through planning and design, research with knowledge is the starting point. By paying attention to students' learning processes, learning methods, and learning abilities, solve the problem of "how to learn" so as to achieve the purpose of implementing classroom teaching content. While improving foreign students' verbal communication ability, they gradually strengthen their pronunciation, spelling and reading skills, vocabulary, and grammar system [22]. On this basis, students are encouraged to expand their reading, cultivate their sense of language, and gradually master Chinese. At the same time, attention should be paid to the influence of mother tongue explanatory language on students' second language learning.

It also analyzes students' learning needs, locks in the need of foreign students to improve their communicative competence in the process of second language acquisition, and focuses on creating vocabulary in which Chinese characters are formed, and the situations in which these characters are formed as little as possible, which will lead to the fear of difficulties and frustration; it also analyzes students' learning needs, locks in the need of foreign students to improve their communicative competence in the process of second language acquisition, and focuses on creating vocabulary in which Chinese characters are formed, and the situations improve your ability to read and understand words based on your perception of communicative competence, laying the groundwork for future reading range expansion.

3.2. Chinese Word Segmentation Algorithm Design. In this paper, the word segmentation algorithm adopts the bidirectional maximum matching algorithm, that is, the materials to be segmented are matched forward and backward, respectively, to obtain two kinds of word segmentation results. Then, the two results are compared, and if the results are consistent, the word segmentation results for materials are considered to be effective, and the results are output; if the results are inconsistent, then the field is regarded as an ambiguous field, and the ambiguity processing stage is entered. The concrete process of the ontology-based bidirectional maximum matching algorithm is shown in Figure 3. This word segmentation method can also be regarded as a method of ambiguity discovery.
In the process of ambiguity detection, it is very difficult to find ambiguity points in word segmentation by using the maximum forward or reverse matching method alone [23]. However, it is easier to find ambiguous fields in the materials to be segmented by comparing the two segmentation results after segmentation with the bidirectional maximum matching method. After the ambiguous field is detected by the above method, the ambiguous field should be processed twice to get the final segmentation result.

Regarding the result of word segmentation as a collection of instances in the ontology library, the relationships between instances in each Chinese sentence can be expressed by a semantic correlation between instances.

The path experienced between instances is defined as $P$ (for two instances with multiple paths, the shortest path is used as the semantic correlation strength between instances). Then, the formula for correlation strength $S_{P}$ between instances is as follows:

$$
S_{P}=\frac{r_{i}+1}{|c|}
$$

where $r_{i}$ represents the weight of each node and $c$ represents all components in the shortest path $P$ except the start node and the end node.

According to formula (1), the semantic correlation $S_{P}$ between the instance and other instances in the context can be calculated. Then, the formula for calculating the semantic correlation strength between the instance and the context is as follows:

$$
\text { relation strength }=\sum_{i=1}^{n} d_{i} \cdot S_{p} .
$$

Among them, $d_{i} \cdot S_{p}$ represents the semantic contribution of the instance feature $d_{i}$ to context $D$. The larger the value of $d_{i} \cdot S_{p}$, the more important the instance feature plays in the sentence and the stronger the semantics it expresses.

The inner product, calculated according to formula (2), indicates the degree of semantic relevance between instance and context. The larger the value, the stronger the semantic relevance between an instance and its context.

The character $y$ and the antecedent character $x$ have a connecting trend, and the smaller the value of $t_{x}, z(y)$, the stronger the connecting trend between them.

$$
t_{x}, z(y)=\frac{(p(z / y)-p(y-x))}{\sqrt{\delta^{2}(p(z / y))+\delta^{2}(p(y / x))}},
$$

where $p(z / y)$ is the conditional probability of $z$ with respect to $y, p(y / x)$ is the conditional probability of $y$ with respect to $x, \delta^{2}(p(z / y))$ represents the variance of $z$ with respect to $y$, and $\delta^{2}(p(y / x))$ represents the variance of $y$ with respect to $x$.

Because of the assumption of the dictionary, words in the dictionary must appear in the real corpus, so expanding the training corpus makes the new training corpus the original training corpus plus words from the dictionary to obtain a new training formula: 


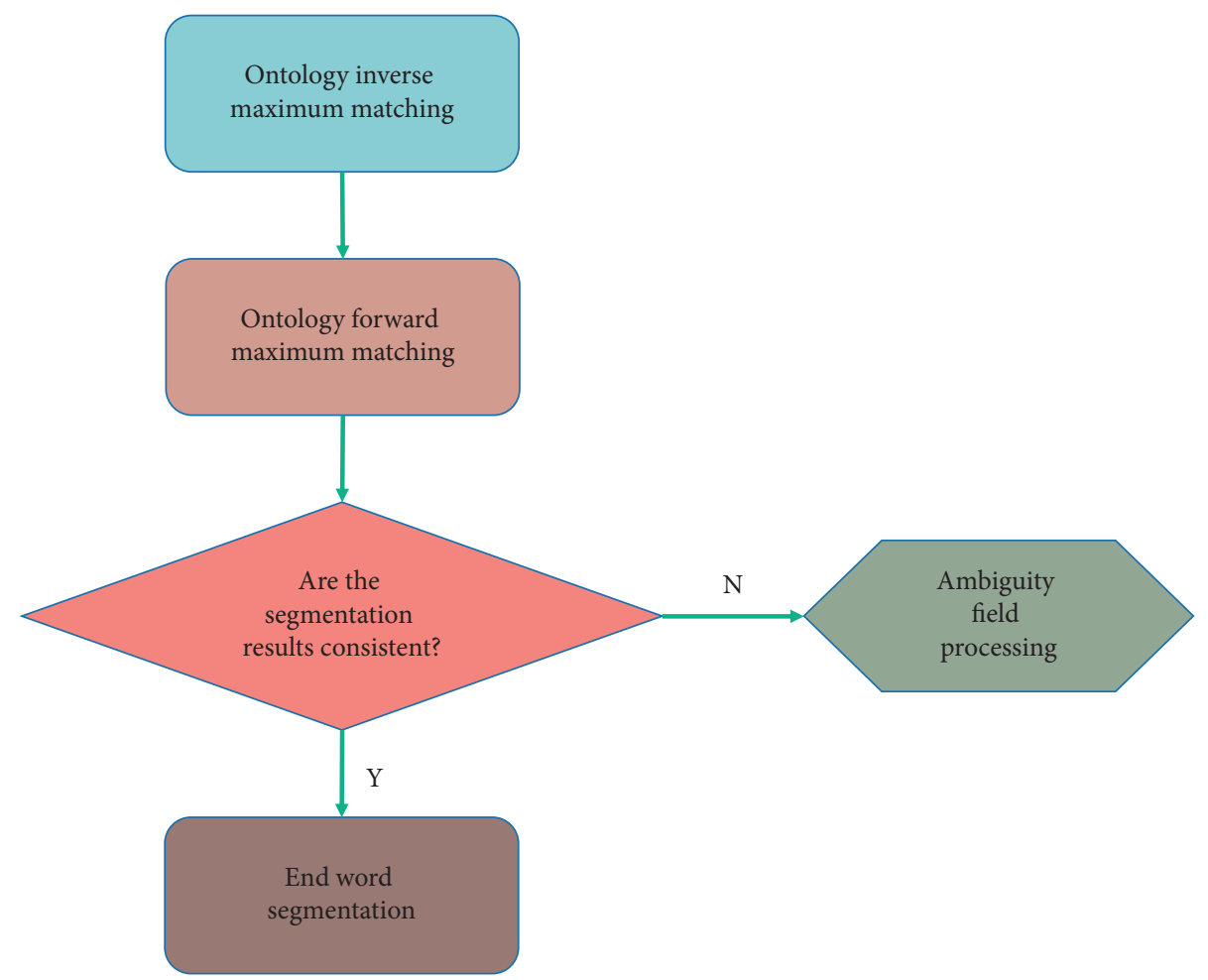

Figure 3: Ontology-based segmentation process of the bidirectional maximum matching method.

$$
P(w)=\frac{\operatorname{Count}(w)+1}{N+|W|}
$$

where $|W|$ is the number of words in the dictionary.

In order to apply the translated word string to the maximum word frequency segmentation algorithm, it is also necessary to determine the word frequency of the string. Let $T$ be a character string composed of words in the word table for translation. Here, a dictionary of translated names is introduced, which includes all character strings composed of words in the dictionary of translated names. The translated dictionary is combined with the common dictionary to get a new dictionary, and the formula for calculating the word frequency of strings is

$$
P(t)=\frac{\operatorname{Count}(t)+1}{N+|W \cup T|}, \quad t \in T .
$$

For a text to be processed, a corresponding dynamic translation dictionary $T_{D}$ is generated, and the elements in $T_{D}$ are all translation word strings appearing in the text to be processed. It can be concluded that, when dealing with the text, the word frequency of the translation dictionary corresponding to the text is as follows:

$$
P(t)=\frac{\text { Count }(t)+1}{N+\left|W \cup T_{D}\right|}, \quad t \in T_{D} .
$$

According to the investigation of Count $(t)$, here Count $(t)$ is the number of times that the translated name $t$ appears in the training corpus. Since most translated names are not included in the ordinary dictionary, the translated name $t$ will not be counted when counting the training corpus, then Count $(t)=0$, that is, for most translated names, its word frequency is a constant.

$$
P(t)=\frac{1}{N+\left|W \cup T_{D}\right|}, \quad t \in T_{D} .
$$

This dictionary of translated names is combined with the common dictionary to create a new dictionary that can be used for maximum word frequency method word segmentation. The algorithm's processing capacity is organically increased by combining the maximum word frequency method and the local frequency method, allowing it to be used for word segmentation of foreign translated names.

\section{Results Analysis and Discussion}

4.1. Understanding and Use of Multimedia Teaching Resources. As we all know, classroom teaching mainly includes hardware and software factors. Hardware factors include teachers, students, and teaching equipment. Software factors include teaching methods adopted by teachers, teachers' teaching ideas, students' learning interests, learning enthusiasm, and learning methods. Therefore, the classroom teaching model is actually a model composed of multidimensional factors.

Teaching ideas are supported by linguistic theory, and it is also the basis of deciding which teaching method to adopt. The deeper a teacher of Chinese characters understands the learning concept of the teaching object, the more effectively he can adjust his teaching concept or educate international students, so that his teaching concept and the students' learning concept can be in harmony. 
As shown in Figure 4, among them, slides, courseware, and electronic lesson plans are frequently used by teachers. These three multimedia teaching resources are the resources that teachers use most in preparing lessons, among which courseware is the most frequently used. This shows that multimedia teaching courseware is the most frequently used multimedia teaching resource for teachers in teaching.

If teachers use multimedia teaching resources in class, more people choose videos and most teachers use the teaching $\mathrm{CD}$ attached to the teaching materials. Because these resources can provide teachers with the required scenarios and demonstrations, it is beneficial to enhance the intuition of teaching and increase the capacity of classroom information.

With the help of multimedia, teachers can communicate intensively and effectively improve the efficiency of classroom teaching. With the multimedia expansion of other situations, the classroom time has been extended, so that students can be consolidated after class and the scope of conversation ability can be extended to all aspects of daily communication. In class, teachers often subconsciously slow down, use complete sentences, and repeat them several times. Every enunciation tries to be clear. However, in actual communication, a sentence passes quickly, and sometimes, even a few phrases with incomplete structure can be used to express it.

The survey results as shown in Figure 5 show that the most frequently used resource types by teachers are text, followed by pictures and videos, and animation is the least frequently used. Talking with teachers, the author understands that most teachers recognize other forms of resources and think that animation and video may better reflect the characteristics of multimedia teaching resources and the advantages that current text textbooks do not have, but they cannot be used in time due to two reasons.

The availability of various types of multimedia teaching resources is uneven. There are few high-quality resources for oral Chinese teaching, including videos, pictures, and animations, and even fewer that can properly display textbook content. Even if there are, entering the classroom is difficult due to production format issues and the large storage capacity of these materials, particularly some video and animation resources.

As a result, teachers should use the complete situational paragraph description as the premise in order to increase the comprehensible input in the classroom, even for teaching simple everyday expressions. As a result, in the same situation, the actual communication session will be much shorter than the paragraph in classroom teaching, giving students the impression that the communication process is moving quickly.

The author conducted an evaluation survey on the main role of multimedia teaching resources in the teaching process by teachers. According to the data in Figure 6, teachers are highly consistent in affirming the positive role of multimedia teaching resources in oral Chinese teaching. However, only $10 \%$ of the students were selected for the option of "informative, improving learning efficiency." Most of the teachers in the interview disagreed with this item.

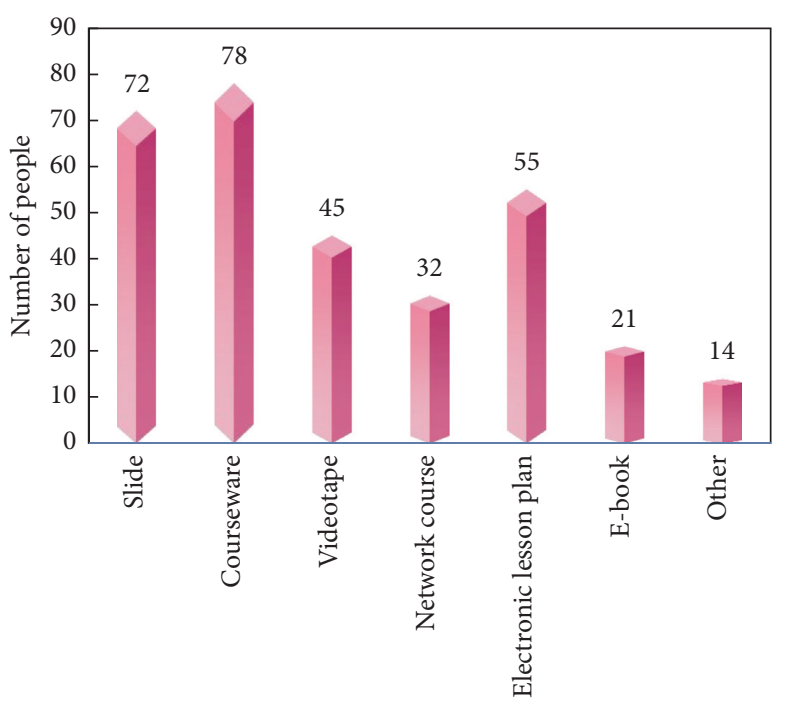

FIgURE 4: Analysis of the forms of multimedia teaching resources used by teachers.

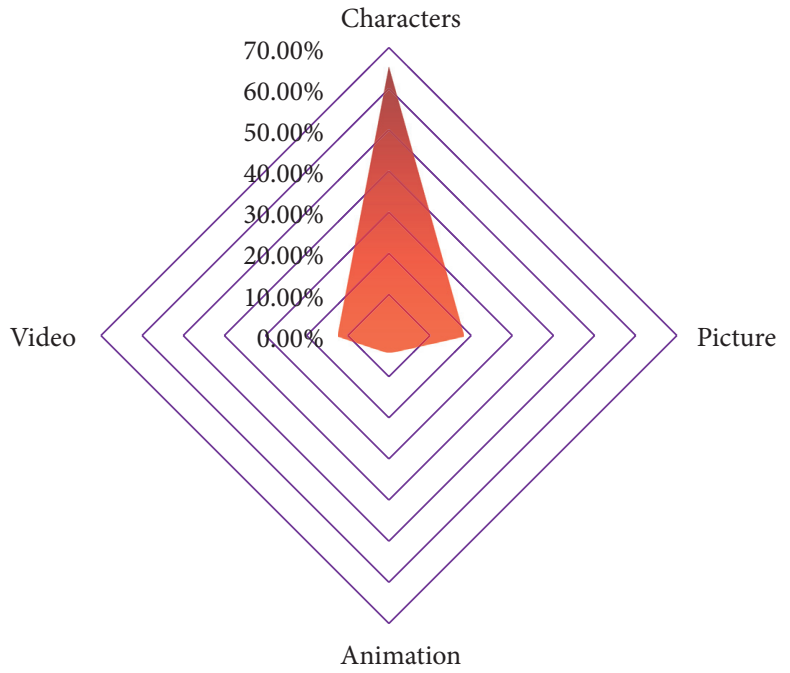

FIgURE 5: Investigation on the frequency of using multimedia teaching resources by teachers.

They said that increasing the amount of information too much could not be well accepted by students, and students' attention was limited, which was not conducive to their learning, which showed that teachers had recognized its two sides and no longer used multimedia blindly.

Regarding the use of words, MIT can realize and demonstrate various forms of exercises such as collocation, expansion, looking at pictures, and talking. Teachers can collect all kinds of pictures, videos, and videos suitable for language situational exercises so that students can practice association and look at pictures and talk according to the information they hear and see, and this will improve students' ability to use the words they have learned in real situations.

Teachers can use multimedia to display the electronic map of the campus and help students strengthen their use of orientation sentences. Regarding the expression of weather, 


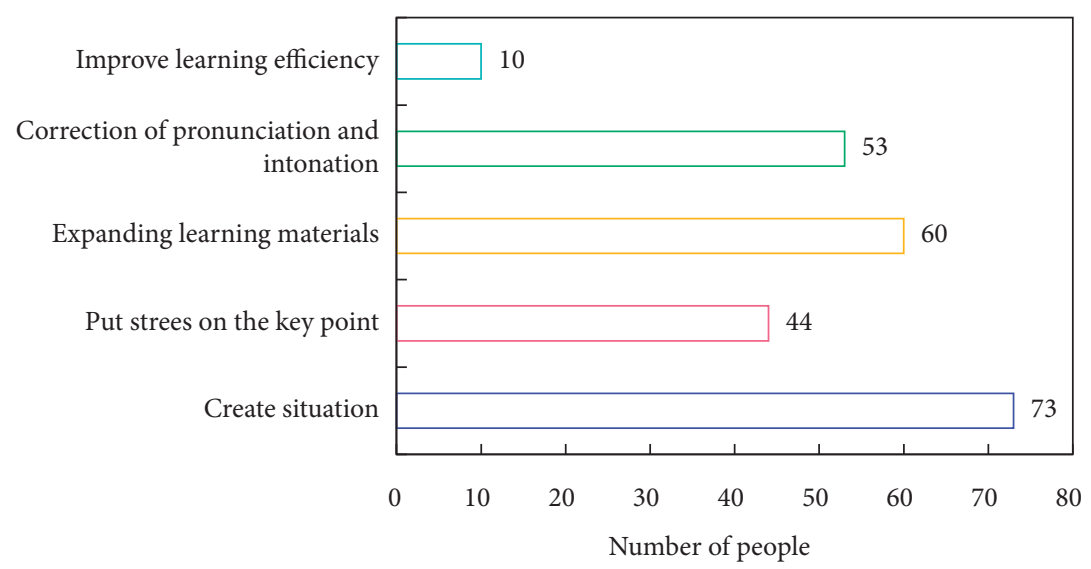

Figure 6: Analysis of the most obvious role in the teaching process.

using screen recording technology, ask students to imitate the weather forecaster to dub according to the pictures and keywords appearing in the barrage, and make a comparison with the standard weather forecast to achieve the purpose of practicing related words and sentence patterns.

4.2. Algorithm Evaluation. MIT's virtual space is very popular among contemporary international students because of its large amount of information content, and convenient, fast, and colorful transmission. They often use the powerful searching ability of the Internet to search for information, dispel doubts, and explore the unknown.

It is necessary to formulate some indicators to evaluate the segmentation results, including $\mathrm{RR}$ (recall rate), AR (accuracy rate), and $\mathrm{F}$ value. For segmentation algorithms, the $\mathrm{F}$ value is usually used as an overall evaluation of the segmentation effect.

In this paper, 50 professional documents in the field of instructional design are segmented, and the statistical results are shown in Figures 7 and 8, in which OFMM is the ontology-based forward maximum matching and ORMM is the ontology-based reverse maximum matching.

Over the years, teachers have used traditional paperbased textbooks for teaching activities, imparting knowledge according to the contents of the paper-based textbooks. Most of these paper-based media present knowledge in one or two dimensions, and the presentation of knowledge is single. Compared with paper-based textbooks, MIT-based multimedia learning materials have more advantages in both the presentation of knowledge and the degree of knowledge implications. Therefore, teachers in the information age should have strong MIT abilities, which include both personal multimedia production ability and multimedia learning resource acquisition and mining ability.

By comparing the values, it can be seen that each index of the ontology-based Chinese character segmentation algorithm is slightly higher than that of the traditional OFMM, ORMM, and hidden Markov model based on mechanical dictionary, which shows that the algorithm has a good segmentation effect in a certain field, but it also has some shortcomings, such as the segmentation of nonprofessional

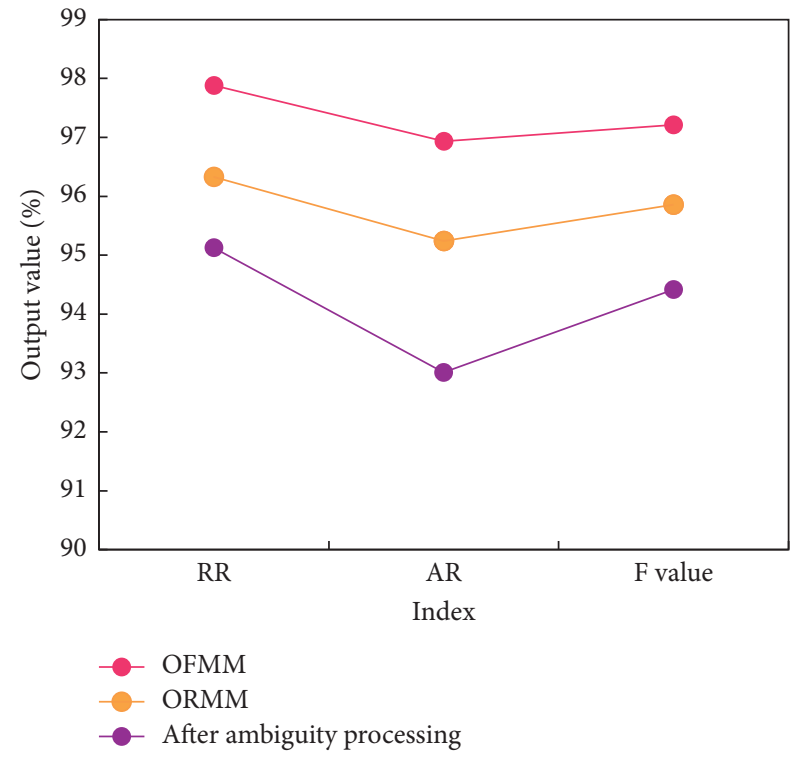

Figure 7: Corpus test data.

words, which can be solved by adding a general vocabulary to the ontology library.

When making teaching courseware, teachers can adjust the appearance and color of the courseware according to students' preferences, which can always achieve the best state visually, give students an aesthetic enjoyment, and attract their interest in learning. Good teaching courseware is when students study, they will not feel the pressure of learning, but instead will feel that they are watching a beautiful object.

In order to verify the universality of this system, this paper selects different disciplines and different scales of text materials to test this algorithm comprehensively [24]. The test results are shown in Figure 9.

According to the statistical data, after improving each block of the Chinese character segmentation algorithm in this paper, the AR and RR of word segmentation are higher than $98 \%$ and $99 \%$, no matter what subject and scale corpus are used to test, which proves that the improved algorithm is indeed effective and can be used as a general-scale utility. 


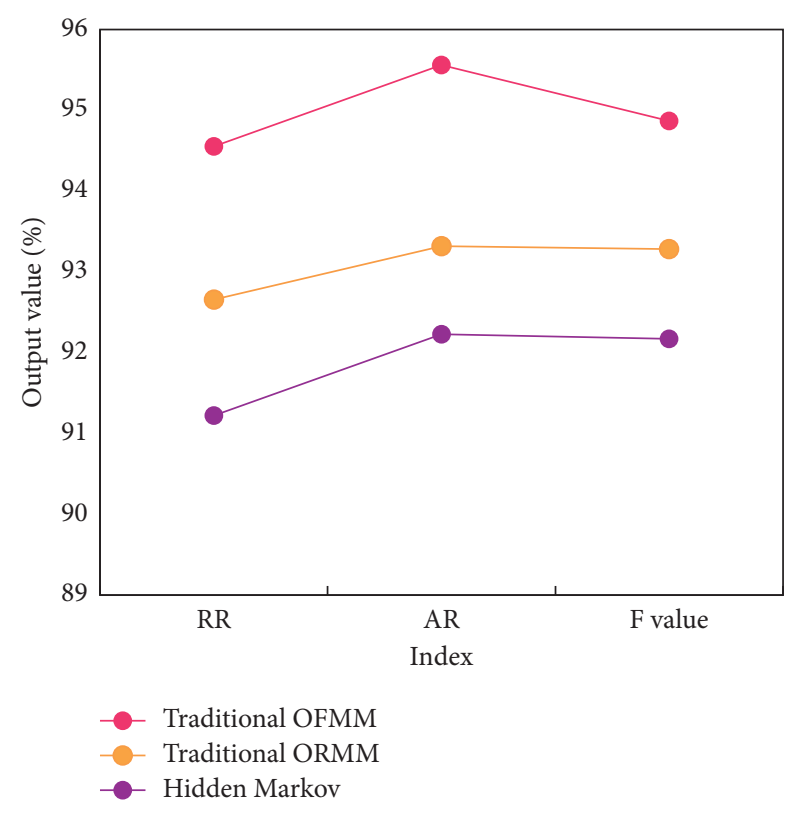

Figure 8: Correlation data.

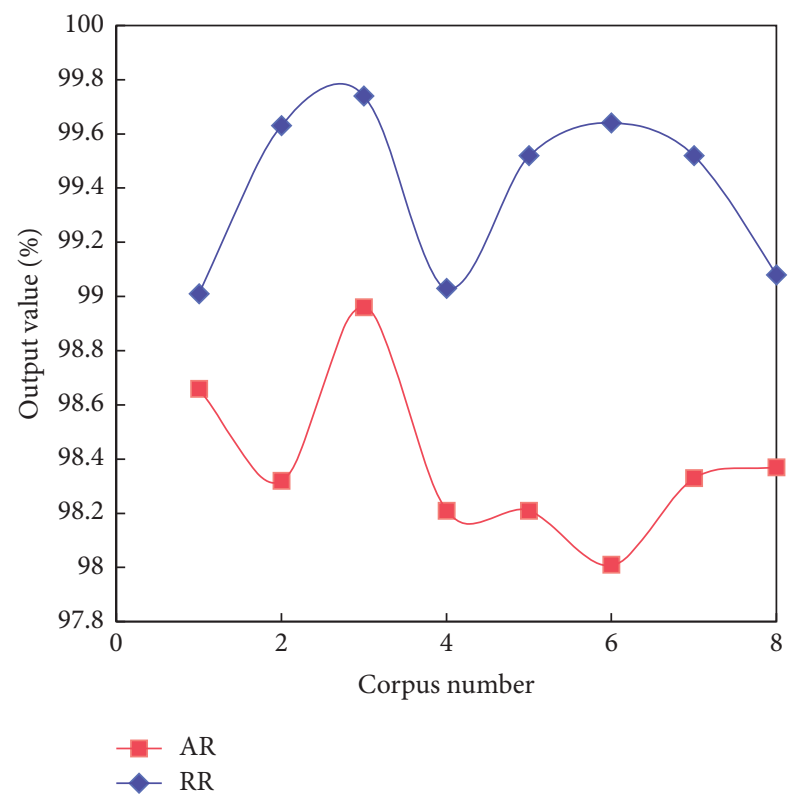

FIGURE 9: Improved word segmentation system.

One of the challenges in the Chinese character segmentation algorithm is ambiguity segmentation. The advantages of bidirectional scanning and a full segmentation algorithm are combined in this paper. The proposed method of bidirectional scanning before full segmentation can theoretically improve segmentation AR, but it is slower than bidirectional scanning. This paper uses a corpus of various disciplines and scales to perform ambiguity segmentation and records their AR and speed in order to show that this improvement is possible. The test data after synthesizing the ambiguity segmentation algorithm is shown in Figure 10.

From the above test data, the AR of ambiguity segmentation is generally maintained at around $80 \%$.

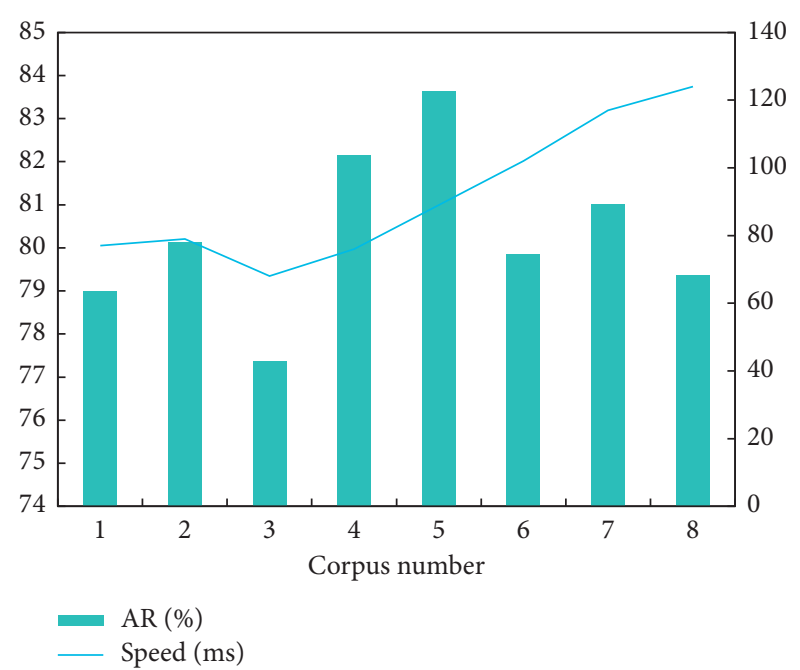

FIGURE 10: Improved ambiguity segmentation algorithm.

Compared with the current general word segmentation algorithm, the ambiguity segmentation algorithm adopted in this paper is slightly improved.

This model has created an open Chinese classroom, provided colorful teaching forms and methods, broadened teaching horizons, enlivened the classroom atmosphere, mobilized students' learning enthusiasm, and improved teaching effect and quality. More importantly, the information-based Chinese classroom can cultivate learners' ability to use Chinese to deal with all kinds of information, self-study, and solve practical problems, create a Chinese learning environment with rich language situations, highlight communicative training and individualized learning, and embody humanity and richness of modern teaching.

MIT is an effective means to optimize the classroom teaching effect, but teachers should treat MIT objectively and not overuse it. If you blindly pursue novel and exciting teaching methods, highlighting MIT as the focus of the classroom, it will not only distract students' attention but also fail to achieve the purpose of improving the classroom teaching effect.

If classroom teaching depends entirely on MIT's display, then teachers will become information players, and both teachers and students will be mechanically led by MIT, which will lead teachers to be too busy to take students' reactions into account, thus reducing the content of teacher-student interaction, reducing students' time and opportunities for free expression and weakening the teachers' role in classroom teaching. Therefore, in the process of using MIT, teachers should not be bound by various forms of MIT. They should pay attention to the interaction between teachers and students from the perspectives of teaching content and students' learning characteristics so as to learn from each other.

\section{Conclusion}

The design of the Chinese character learning information platform needs to organize and design the resources and contents in close connection with the actual needs of 
teaching, manage the resource pool, and design the functions of the application system based on practical principles. Chinese character learning and teaching based on MIT can break the fixed pattern of traditional Chinese teaching, accelerate the improvement of teaching content and methods, and better serve Chinese teaching. As the basic subject of Chinese character information processing, Chinese character segmentation technology is the initial step for human beings to intelligently process Chinese character information. By simply identifying the named entities in the materials, the materials to be segmented are segmented for the first time, which greatly reduces the complexity of segmentation and saves the time of segmentation. A series of experimental tests proved that the ontology-based Chinese character segmentation algorithm had a certain improvement in AR and RR of segmentation results compared with the traditional dictionary-based Chinese character segmentation algorithm.

Although the application of ontology-based word segmentation algorithms has made some progress in word segmentation $\mathrm{AR}$ and $\mathrm{RR}$, this method has not completely solved all the problems existing in the word segmentation process. It is necessary to improve the identification method of unknown words in the algorithm so that the system can more accurately identify unknown words in the materials to be segmented and identify unknown words that only appear once in the materials.

\section{Data Availability}

The data used to support the findings of this study are included within the article.

\section{Conflicts of Interest}

The authors do not have any possible conflicts of interest with this study.

\section{References}

[1] J. Shen, M. Wang, and T.-S. Chua, "Accurate online video tagging via probabilistic hybrid modeling," Multimedia Systems, vol. 22, no. 1, pp. 99-113, 2016.

[2] A. O. Ojo, M. Raman, and A. G. Downe, "Toward green computing practices: a Malaysian study of green belief and attitude among Information Technology professionals," Journal of Cleaner Production, vol. 224, no. 7, pp. 246-255, 2019.

[3] F. Alzamzami, M. Saini, and A. El Saddik, "DST: days spent together using soft sensory information on OSNs-a case study on Facebook," Soft Computing, vol. 21, no. 15, pp. 4227-4238, 2017.

[4] H.-Y. Hsiung, Y.-L. Chang, H.-C. Chen, and Y.-T. Sung, "Effect of stroke-order learning and handwriting exercises on recognizing and writing Chinese characters by Chinese as a foreign language learners," Computers in Human Behavior, vol. 74, no. 9, pp. 303-310, 2017.

[5] N. Meng, A. Y. Lim, and N. H. Choi, "The factors influencing narrative attractiveness and ideal self-reference in Chinese consumers' evaluation of Korean soap operas and transportation," International Business Review, vol. 21, no. 1, pp. 1-26, 2017.

[6] L. Qiujun, M. Haojie, and L. Gang, "Characters-based sentiment identification method for short and informal Chinese text," Interlending and Document Supply, vol. 46, no. 1, pp. 57-66, 2018.

[7] M. A. Mastropieri, T. E. Scruggs, and J. R. Levin, "Direct vs. mnemonic instruction: relative benefits for exceptional learners," The Journal of Special Education, vol. 20, no. 3, pp. 299-308, 2016.

[8] T. Li, Y. Wang, X. Tong, and C. McBride, "A developmental study of Chinese children's word and character reading," Journal of Psycholinguistic Research, vol. 46, no. 1, pp. 141-155, 2017.

[9] J. Nirme, M. Haake, A. Gulz, and M. Gullberg, "Motion capture-based animated characters for the study of speechgesture integration," Behavior Research Methods, vol. 52, no. 3, pp. 1339-1354, 2020.

[10] L. A. Orthia and R. Morgain, "The gendered culture of scientific competence: a study of scientist characters in doctor who 1963-2013," Sex Roles, vol. 75, no. 3-4, pp. 79-94, 2016.

[11] N. Lin, B. Angele, H. Hua, W. Shen, J. Zhou, and X. Li, "Skipping of Chinese characters does not rely on word-based processing," Attention, Perception, \& Psychophysics, vol. 80, no. 2, pp. 1-8, 2017.

[12] Y.-L. Tzeng, C.-H. Hsu, W.-H. Lin, and C.-Y. Lee, "Impaired orthographic processing in Chinese dyslexic children: evidence from the lexicality effect on N400," Scientific Studies of Reading, vol. 22, no. 1, pp. 85-100, 2018.

[13] L. Cardenas Cantos, J. Lopez Izquierdo, and E. Cardenas Cantos, "Interactive multimedia application for teaching and learning in Analytical Geometry," IEEE Latin America Transactions, vol. 14, no. 7, pp. 3461-3466, 2016.

[14] M. Torres and G. Qiu, "Habitat image annotation with lowlevel features, medium-level knowledge and location information," Multimedia Systems, vol. 22, no. 6, pp. 1-16, 2016.

[15] H. Hartman and P. Johnson, "The effectiveness of multimedia for teaching drug mechanisms of action to undergraduate health students," Computers \& Education, vol. 125, no. 10, pp. 202-211, 2018.

[16] E. Hornecker and M. Honauer, "Creating performance-oriented multimedia projects as part of an interdisciplinary teaching practice," IEEE Multimedia, vol. 25, no. 2, pp. 93-103, 2018.

[17] H.-Y. Lee and H. Hwang, "Gradient of learnability in teaching English pronunciation to Korean learners," Journal of the Acoustical Society of America, vol. 139, no. 4, pp. 1859-1872, 2016.

[18] T.-H. Jiang, S.-L. Chen, and J. K. C. Chen, "Examining the role of behavioral intention on multimedia teaching materials using FSQCA," Journal of Business Research, vol. 69, no. 6, pp. 2252-2258, 2016.

[19] S. Graham and K. R. Harris, "Implications of constructivism for teaching writing to students with special needs," The Journal of Special Education, vol. 28, no. 3, pp. 275-289, 2016.

[20] R. Thomson and G. Wilson, "Promoting staff learning about assessment through digital representations of practice: evaluating a pilot project," Australasian Journal of Educational Technology, vol. 24, no. 2, pp. 143-149, 2018.

[21] J. Manuel and D. Carter, "Sustaining hope and possibility: early-career English teachers' perspectives on their first years of teaching," English in Australia, vol. 51, no. 1, pp. 91-103, 2016. 
[22] M. Porto, A. Montemayor-Borsinger, and M. López-Barrios, "Research on English language teaching and learning in Argentina (2007-2013)," Language Teaching, vol. 49, no. 3, pp. 356-389, 2016.

[23] J. Harmer, "The practice of English language teaching," ELT Journal, vol. 32, no. 4, pp. 401-405, 2016.

[24] I. Reid, "Literary experience and literature teaching since the growth model," English in Australia, vol. 51, no. 3, pp. 11-18, 2016. 